\title{
Risk identification of agricultural drought for sustainable Agroecosystems
}

\author{
N. R. Dalezios ${ }^{1,2}$, A. Blanta ${ }^{1}$, N. V. Spyropoulos ${ }^{2}$, and A. M. Tarquis ${ }^{3}$ \\ ${ }^{1}$ Laboratory of Hydrology, Department of Civil Engineering, University of Thessaly, Volos, Greece \\ ${ }^{2}$ Department of Natural Resources Development and Agricultural Engineering, Agricultural University of Athens, \\ Athens, Greece \\ ${ }^{3}$ CEIGRAM, Technical University of Madrid, Madrid, Spain
}

Correspondence to: N. R. Dalezios (dalezios.n.r@gmail.com)

Received: 28 February 2014 - Published in Nat. Hazards Earth Syst. Sci. Discuss.: 30 April 2014

Revised: - - Accepted: 29 July 2014 - Published: 12 September 2014

\begin{abstract}
Drought is considered as one of the major natural hazards with a significant impact on agriculture, environment, society and economy. Droughts affect sustainability of agriculture and may result in environmental degradation of a region, which is one of the factors contributing to the vulnerability of agriculture. This paper addresses agrometeorological or agricultural drought within the risk management framework. Risk management consists of risk assessment, as well as a feedback on the adopted risk reduction measures. And risk assessment comprises three distinct steps, namely risk identification, risk estimation and risk evaluation. This paper deals with risk identification of agricultural drought, which involves drought quantification and monitoring, as well as statistical inference. For the quantitative assessment of agricultural drought, as well as the computation of spatiotemporal features, one of the most reliable and widely used indices is applied, namely the vegetation health index (VHI). The computation of VHI is based on satellite data of temperature and the normalized difference vegetation index (NDVI). The spatiotemporal features of drought, which are extracted from VHI, are areal extent, onset and end time, duration and severity. In this paper, a 20year (1981-2001) time series of the National Oceanic and Atmospheric Administration/advanced very high resolution radiometer (NOAA/AVHRR) satellite data is used, where monthly images of VHI are extracted. Application is implemented in Thessaly, which is the major agricultural droughtprone region of Greece, characterized by vulnerable agriculture. The results show that agricultural drought appears every year during the warm season in the region. The severity
\end{abstract}

of drought is increasing from mild to extreme throughout the warm season, with peaks appearing in the summer. Similarly, the areal extent of drought is also increasing during the warm season, whereas the number of extreme drought pixels is much less than those of mild to moderate drought throughout the warm season. Finally, the areas with diachronic drought persistence can be located. Drought early warning is developed using empirical functional relationships of severity and areal extent. In particular, two second-order polynomials are fitted, one for low and the other for high severity drought classes, respectively. The two fitted curves offer a forecasting tool on a monthly basis from May to October. The results of this drought risk identification effort are considered quite satisfactory offering a prognostic potential. The adopted remote-sensing data and methods have proven very effective in delineating spatial variability and features in drought quantification and monitoring.

\section{Introduction}

Agriculture faces many challenges over the coming years, such as international competition and further liberalization of trade policy. Moreover, agricultural production is highly dependent on climate, and is adversely affected by anthropogenic climate change and increasing climate variability leading to increases in climate extremes (Sivakumar et al., 2005). Under a changing climate, the role of agriculture as provider of environmental and ecosystem services will gain further importance. On the other hand, natural disasters play 
a major role in agricultural development, and the economic cost associated with all natural disasters has increased significantly (Salinger et al., 2005). Current scientific projections point to changes, among others, in climate extremes, such as heatwaves, heavy rainfall and droughts, in many areas including southern Europe. In fact, the entire Mediterranean basin is characterized as a vulnerable area affecting agriculture due to the combined effect of reduced precipitation and temperature increases in areas already coping with water scarcity. Agricultural production risks could become an issue in southern Europe, as mainly droughts and heatwaves are likely to increase the incidence of crop failure. As yield variability increases, the food supply is at increasing risk.

Environmental degradation is one of the major factors contributing to the vulnerability of agriculture, because it directly magnifies the risk of natural disasters. Vulnerability of agriculture can be reduced through adaptation measures and tools to increasing climate variability (EU, 2007). In order to ensure sustainability in agricultural production, a better understanding of the natural disasters that impact agriculture, in particular droughts, is essential. Drought is considered as one of the major natural hazards with a significant impact on the environment, society, agriculture and economy. By considering drought as a hazard, drought types are classified into three categories, namely meteorological or climatological drought, agrometeorological or agricultural drought and hydrological drought, and as a fourth class, the socioeconomic drought impacts can also be considered (Keyantash and Dracup, 2002). Indeed, mainly agricultural droughts affect sustainability of agriculture and may result in environmental degradation of a region, which is one of the factors contributing to the vulnerability of agriculture, as already mentioned above. A comprehensive assessment of the impacts of droughts on agriculture requires a multidisciplinary, multi-sectoral and integral approach involving, among other factors, the understanding of the physical and biological factors contributing to droughts. Moreover, the improvement of drought prediction and early warning methods, as well as dissemination of warnings, requires a continuous effort, which needs to be expanded and intensified. Needless to say, the emphasis should remain on vulnerability and drought impact assessment techniques and preparedness and mitigation strategies.

From the beginning of 21st century, there is an awareness of risk in the environment, along with a growing concern for the continuing potential damage caused by hazards (Tarquis et al., 2013). Gradually, a more integrated approach to environmental hazards, including droughts, has been attempted using common methodologies, such as risk analysis, which involves risk management and risk assessment (Peng et al., 2009; Shahid and Behrawan, 2008; Wu and Wilhite, 2004). Indeed, risk management means reducing the threats posed by known hazards, whilst at the same time accepting unmanageable risks and maximizing any related benefits. Risk assessment constitutes the first part within the risk management framework and involves evaluating the importance of a risk, either quantitatively or qualitatively. Risk assessment consists of three steps (Smith, 2001), namely risk identification, risk estimation and risk evaluation. Nevertheless, the risk management framework also includes a fourth step, i.e. the need for a feedback of all the risk assessment undertakings. However, there is a lack of such feedback, which constitutes a serious deficiency in the reduction of environmental hazards at the present time.

There is an increasing trend for the use of remote sensing in drought assessment, mainly due to the growing number and efficiency of earth-observation satellite systems, along with the increasing reliability of remote-sensing methods (Dalezios et al., 2012a; Kanellou et al., 2012). Specifically, remote-sensing data and methods can be employed in several aspects of drought, such as vulnerability, damage assessment and warning. Remote-sensing contributions can be focused on relief and, possibly, preparedness or warning (Foot, 1993), although, in many cases, remote sensing can also contribute to disaster prevention, where frequency of observation is not such a prohibitive limitation. This is why a major consideration for remote sensing use in drought assessment and disaster reduction is the extent to which operational users can rely on a continued supply of data (McVicar and Jupp, 1998; Thenkabail et al., 2004). Indeed, satellite systems provide temporally and spatially continuous data over the globe and, thus, they are potentially better and relatively inexpensive tools for regional applications, such as monitoring vegetation conditions, agricultural drought and crop yield assessment than conventional weather data (Domenikiotis et al., 2004). For these types of applications, appropriate remotesensing systems are those that provide low spatial and high temporal resolution data, since daily coverage and data acquisition are necessary. The series of geosynchronous, polarorbiting meteorological satellites National Oceanic and Atmospheric Administration/advanced very high resolution radiometer (NOAA/AVHRR) fulfill the above requirements, and there are already long series of databases.

In addition, remote sensing is a useful tool to analyse the vegetation dynamics on local, regional or global scales (Kogan, 2001), to assess the vegetative stress and to determine the impact of climate on vegetation (Wang et al., 2003). Satellite-derived vegetation indices have been extensively used for identifying periods of vegetative stress in crops, which represents an indication of agricultural drought, or generally vegetation (Dalezios et al., 2012b; Kogan, 2001; Domenikiotis et al., 2002). Specifically, the NOAA/AVHRR derived normalized difference vegetation index (NDVI) has been used in drought detection and mapping (Kogan, 1995; Tucker and Choudhuri, 1987). NDVI is a quick and efficient way for the estimation of vivid vegetation. Furthermore, NDVI is indicative of the level of photosynthetic activity in vegetation and, during vegetative stress periods, results in 
significant reduction in NDVI values, corresponding occasionally to a complete lack of chlorophyll elements.

Agricultural drought is described in terms of crop failure and exists when soil moisture is depleted so that crop yield is considerably reduced. Indeed, crop growth and yield are largely dependent on water availability (Heim, 2002). This paper deals with the quantitative risk assessment of agricultural drought affecting agriculture and its sustainability. For clarification purposes, in this paper, the term "agricultural drought" is used, which is already an established term in international literature. The objective of the paper consists of considering and analysing the risk identification component of agricultural drought within the risk management framework. Risk identification of agricultural drought involves drought quantification, monitoring including early warning, as well as statistical inference. For the quantitative assessment of agricultural drought, as well as the computation of spatiotemporal features, one of the most reliable and widely used indices is applied, namely the vegetation health index (VHI). The VHI is a combination of the vegetation condition index (VCI) and the temperature condition index (TCI) derived from NOAA/AVHRR satellite data (Kogan, 2001). In Greece, VCI and TCI, as well as the adjusted VHI, have proven to be useful tools for the detection of agricultural drought and for monitoring agricultural crops (Dalezios et al., 2012b; Domenikiotis et al., 2002; Tsiros et al., 2004). The paper is organized as follows: in Sect. 2, drought types are defined and the concept of drought risk assessment is presented. In Sect. 3, the risk identification methodology of agricultural drought is developed, including quantification, monitoring and features of drought, along with the remotesensing potential, as well as the study area and database. Finally, in Sect. 4, results are analysed and discussed.

\section{Conceptualizing drought and drought risk}

Droughts are part of nature's climate variability. Droughts originate from a deficiency of precipitation over an extended period of time resulting in a water shortage for some activity, group or environmental sector. Droughts differ from other environmental hazards due to several unique characteristics, such as its slow onset (often characterized as a creeping phenomenon), the absence of a precise and universal definition leading to inaction, and its non-structural impacts, which can be local or regional and can last for a long time or a very short time (Wu and Wilhite, 2004). Moreover, the impacts of droughts on agriculture may be severe and are neither immediate nor easily measured. All of these make assessment and response difficult and mitigation actions less obvious, resulting into slow progress on drought preparedness.

\subsection{Drought types and definitions}

By considering drought as a hazard, there is a tendency to define and classify droughts into different types. Definitions of drought can be categorized into two types: conceptual and operational. Conceptual definitions are general and help the public to understand the concept of drought. Operational definitions help in identifying the duration and severity of drought and are more useful in recognizing and planning for drought. Three operational definitions are presented, namely meteorological or climatological, agrometeorological or agricultural and hydrological drought. With the exception of meteorological drought, the other types of drought, such as agricultural and hydrological, emphasize the human or social aspects of drought, in terms of the interaction between the natural characteristics of meteorological drought and human activities that depend on precipitation to provide adequate water supplies to meet societal and environmental demands. Figure 1 presents the temporal development of the sequence of the different drought types, as proposed by the US National Drought Center at the University of Nebraska (Wilhite et al., 2000).

Meteorological drought is a region-specific natural event, due to the regional nature of atmospheric phenomena, resulting from multiple causes. It is defined as the degree of dryness that is specified by deficiencies of precipitation and the dry period duration. Agricultural drought refers to the agricultural impacts resulting from deficiencies in water availability for agricultural use. Indeed, agricultural drought is defined by the availability of soil water to support crop and forage growth, and there is no direct relationship between precipitation and infiltration of precipitation into the soil. Indeed, infiltration depends on antecedent moisture conditions, soil type, slope and precipitation intensity. Soils with low water-holding capacity are typical of drought-prone areas, which are more vulnerable to agricultural drought. Hydrological drought is normally defined by the departure of surface and subsurface water from some average conditions over a long time period resulting from meteorological drought. Like agricultural drought, there is no direct relationship between precipitation amounts and the status of surface and subsurface water supplies. There is also significant time lag between departures of precipitation and the appearance of these deficiencies in surface and subsurface components of the hydrological system (Sivakumar et al., 2010). All these drought types along with the temporal sequence of procedures are shown schematically in Fig. 1 (Wilhite et al., 2000). Finally, socioeconomic drought refers to the gap between supply and demand of economic goods brought on by the three other types of drought described earlier, such as water, food, raw materials, transportation and hydroelectric power, as a result of a weather-related shortfall in water supply. Socioeconomic drought is different from other types of drought, since its occurrence depends on the spatiotemporal processes of supply and demand. 
Table 1. Conventional and satellite data-based drought indices (from Kanellou et al., 2009b).

\begin{tabular}{ll}
\hline Conventional drought indices & Satellite data-based drought indices \\
\hline 1. Percent of normal & 1. Normalized difference vegetation index \\
2. Discrete and cumulative precipitation anomalies & 2. Deviation NDVI index \\
3. Rainfall deciles & 3. Enhanced vegetation index \\
4. Drought area index & 4. Vegetation condition index \\
5. Rainfall anomaly index & 5. Monthly vegetation condition index \\
6. Standardized precipitation index & 6. Temperature condition index \\
7. Effective drought index & 7. Vegetation health index \\
8. Palmer drought indices & 8. Normalized difference temperature index \\
9. Crop moisture index & 9. Crop water stress index \\
10. Bhalme-Mooley drought index & 10. Drought severity index \\
11. Surface water supply index & 11. Temperature-vegetation dryness index \\
12. Reclamation drought index & 12. Normalized difference water index \\
13. Total water deficit & \\
14. Cumulative streamflow anomaly & \\
15. Computed soil moisture & \\
16. Soil moisture anomaly index & \\
17. Agro-hydro potential & \\
18. Drought indices derived from flow data & \\
19. Standardized water-level index & \\
20. Reconnaissance drought index &
\end{tabular}

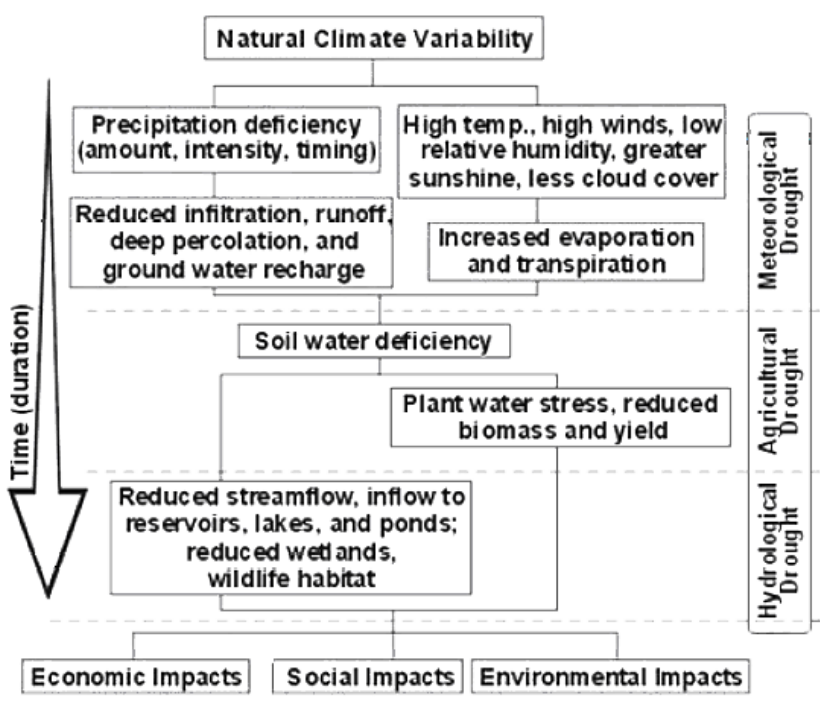

Figure 1. Drought types and temporal sequential procedure (from US National Drought Center, University of Nebraska).

Droughts result in several significant impacts, which can be defined as direct and indirect. Direct drought impacts include reduced cropland, forest and rangeland productivity, reduced water levels, increased fire hazards, livestock and wildlife mortality rates, as well as damage to wildlife and fish habitat. The consequences of these direct impacts are considered as indirect impacts. Moreover, drought impacts can also be classified by the affected sector, leading to environmental, economic or social types of impact. Specifically, environmental impacts refer to the losses resulted as a direct consequence of drought or indirectly, such as wildfire damage to plant and animal species. Similarly, many economic impacts affect agriculture and related sectors. Finally, social impacts refer to public safety, health, quality of life issues, water-use conflicts and regional inequities in relief and impacts distribution.

Quantification of drought is accomplished through drought indicators, which are variables describing drought features, such as magnitude, duration, severity, areal extent, onset and end time (Dalezios et al., 2000). Primary data for meteorological, agricultural or hydrological drought indicators are climate variables, such as temperature and precipitation, streamflows, soil moisture, reservoir storage, groundwater levels, snow pack and vegetation. Data analysis, interpretation and aggregation leads to drought indicators, where several of them can be synthesized into a single indicator on a quantitative scale, often called a drought index. There are questions about the scientific and operational validity of an index, i.e. how each indicator is combined and weighted in the index and how an index value is related to geophysical and statistical characteristics of drought (Steinemann et al., 2005). Nevertheless, drought indices can provide ease of implementation and are extensively used in drought quantification and risk assessment (Farrell et al., 2010).

There are several review studies on the use of drought indices based on conventional and/or remotely sensed data (Mishra and Singh, 2010; Kanellou et al., 2009a; Heim, 2002). Table 1 presents a number of commonly used drought indices based on both conventional (ground) and satellite 
data (Kanellou et al., 2009b). In order to assess and monitor drought episodes and to alleviate the impacts of droughts it is necessary to detect several spatiotemporal drought features, as mentioned above, and to link drought variability to climate and its variability (Piechota and Dracup, 1996). Moreover, remote sensing has gradually become an important tool for the detection of the spatial and temporal distribution and characteristics of drought at different scales (Steven and Jaggard, 1995). At the present time, the growing number and efficiency of earth observation satellite systems, along with the increasing reliability of remote-sensing methodologies, provide a range of new capabilities in monitoring drought and assessing its effect. In this paper, the remote-sensing potential is explored in terms of data and methods in order to quantify agricultural drought and assess several drought features and characteristics.

\subsection{Drought risk concepts}

It is significant and very useful to address and clarify basic terms of risk analysis. Firstly, hazard is an inescapable part of life. Indeed, hazard is best viewed as a naturally occurring or human-induced process or event, with the potential to create loss, i.e. a general source of future danger. On the other hand, risk is sometimes taken as synonymous with hazard, but risk has the additional implication of the chance of a particular hazard actually occurring. In fact, risk is the actual exposure of something of human value to a hazard and is often regarded as the product of probability and loss. Based on the above, hazard (or cause) may be defined as "a potential threat to humans and their welfare" and risk (or consequence) as "the probability of a hazard occurring and creating loss" (Smith, 2001). Unlike hazard and risk, a disaster is an actual happening, rather than a potential threat, thus, a disaster may be defined as "the realization of hazard". The term environmental hazard has the advantage of including a wide variety of hazard types ranging from "natural" (geophysical) events, through "technological" (man-made) events to "social" (human behaviour) events.

The concept of vulnerability, like hazard and risk, indicates a possible future state. It implies a measure of risk combined with a relative inability to cope with the resulting stress. Vulnerability can be assessed by the adverse reaction of a system, or part of a system to the occurrence of a hazardous event (Salinger et al., 2005). United Nations International Strategy for Disaster Reduction (UNISDR) (2005) reached the following definition: "the conditions determined by physical, social, economic and environmental factors or processes, which increase the susceptibility of a community to the impact of hazards". Most approaches to reduce system-scale vulnerability can be viewed as expressions of either resilience or reliability. Moreover, vulnerability refers to the characteristics of populations, activities and the environment that make the population susceptible to the effects of a drought, and is measured by the ability to anticipate, to deal with, to resist and recover from drought. Vulnerability assessment provides a framework for identifying or predicting the underlying causes of drought impacts. As drought hazard is a potential threat, it is important to assess the risk associated with the drought hazard based on an assumed exposure and coping capacity of the system. Thus, vulnerability of the system with regards to the hazard implies the lack of the system's capacity to cope with the hazard and its consequences. The vulnerability of a system towards drought can be decomposed into the vulnerability of each element of the system. Indeed, vulnerability is dependent on several factors, such as the state of the system, the magnitude of the phenomenon, the social factor and the exposure of an element or a system to a certain hazard and is expressed as a function of the above factors or variables.

Besides physical protection, a synthesis of anti-hazard measures starts being considered, including land use management, better planning for response and recovery and emergency warnings. The recent (2012) special report on managing the risks of extreme events and disasters to advance climate change adaptation (SREX) from the IPCC (Intergovernmental Panel for Climate Change) focuses on the relationship between climate change and extreme weather and climate events, the impacts of such events, and the strategies of managing the associated risks (IPCC, 2012). Understanding of extreme events and disasters is a prerequisite for the development of adaptation strategies in the context of climate change and risk reduction within the disaster risk management framework. Extreme events and disasters, such as droughts, are expected to have greater impacts on sectors with closer links to climate, such as agriculture and food security.

For the calculation of risk for each drought episode, the impacts and implications on the system have to be estimated. Specifically, if water shortage and impact assessment addressed jointly, this leads to the estimation of vulnerability and risk. Indeed, agricultural drought can be directly associated to these impacts. In order to reduce the drought risk, vulnerability of the affected system can be reduced by improving its conditions through decreasing the magnitude of the water shortage and its consequences and through improving the public capacity. In fact, the vulnerability reduction of a system is the most important step for reducing the drought risk. This can be achieved by a well-structured preparedness plan, which has to be developed with the participation also of stakeholders and long before any expected drought episodes (Dalezios et al., 2009). Risk can be computed as a functional relationship of hazard and vulnerability, shown in Fig. 2. Furthermore, Fig. 3 presents a list of the components of drought risk management framework, which include risk assessment and risk governance.

The subject of risk analysis, as already mentioned, involves risk management and risk assessment in order to investigate and better understand the problem of drought hazard with the objective to develop proactive measures and 


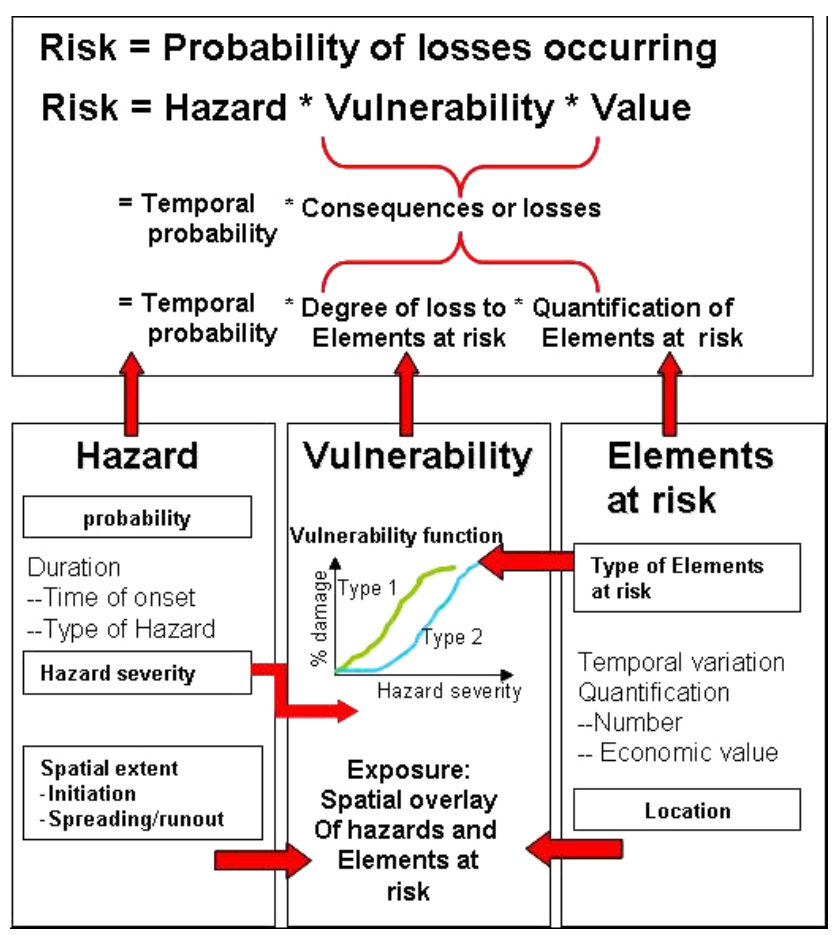

Figure 2. Definition of Risk Concept.

procedures before a crisis. In turn, it is stated that risk management covers the risk assessment component either quantitatively or qualitatively, along with risk governance, which involves a feedback by all the affected parties. Moreover, quantitative risk assessment consists of three components, namely risk identification, risk estimation and risk evaluation (Smith, 2001). Specifically, risk identification involves hazard quantification and their interactions, event monitoring and hazard modelling, statistical inference, as well as the development of a database, which is based on recorded historical environmental data of the study area. This is where historical information on drought and its effect is analysed. Similarly, risk estimation involves the risk of such events, i.e. event probabilities, as well as magnitudeduration-frequency and areal extent relationships for hazard assessment. Finally, risk evaluation includes environmental impact assessment, cost-benefit analysis of adaptation options for the development of mitigation measures.

\section{Risk identification of agricultural drought}

This section covers the development of risk identification for agricultural drought, which is a component of drought risk assessment within the risk management framework. As already mentioned, drought risk identification involves quantification and modelling of agricultural drought, and drought monitoring, including early warning, statistical inference and the development of a database. At first, the study area is de-
Risk Management

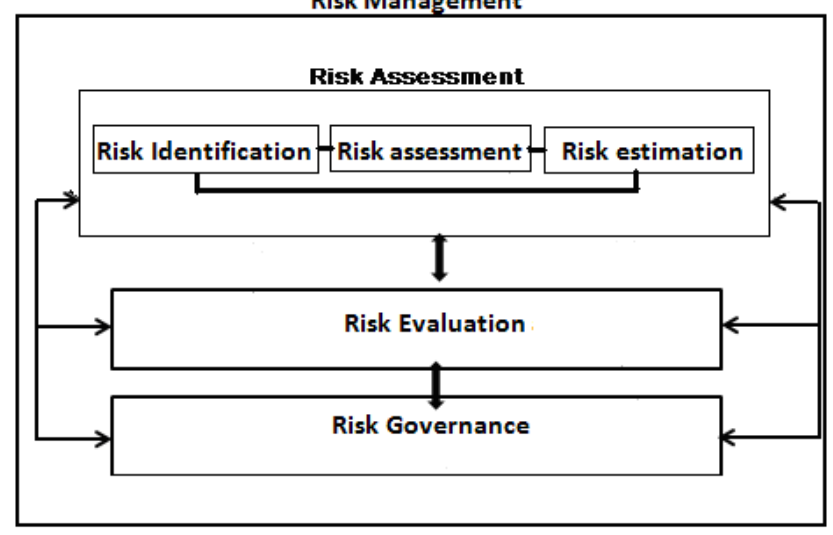

Figure 3. Components of drought risk management.

scribed showing the need for vulnerability assessment, which affects agriculture and its sustainability. Then, the database is presented, which consists of satellite and conventional data and is based on recorded historical environmental data of the study area. For the quantification of agricultural drought, one of the most reliable and widely used indices is applied, namely the VHI. The spatiotemporal features of drought are then described, which are extracted from the VHI, and are the areal extent, onset and end time, duration and severity of drought. For monitoring of agricultural drought, empirical models, which relate drought severity to areal extent based on VHI values during the growing season, and provide a prognostic ability for potential drought occurrence during the warm season are also developed, based on satellite data.

\subsection{Study area and database}

\subsubsection{Study area}

Thessaly is located in the central part of Greece and has a total area of $14036 \mathrm{~km}^{2}$, which roughly represents $10.6 \%$ of the whole country. Moreover, in Thessaly, $36 \%$ of the land is flat and $17.1 \%$ is semi-mountainous, whereas the remaining $44.9 \%$ is mountainous. The region of Thessaly is characterized by a highly variable landscape, and the terrain is such that high mountains surround the plain, which is the largest in the country (Fig. 4). The plain of Thessaly is crossed by Pinios river with several tributaries, namely Titarisios, Malakasiotikos, Litheos, Portaikos, Pamisos and Farsaliotis. Thessaly water district is divided into three watersheds: the main one is called the Pinios watershed with a size of $9500 \mathrm{~km}^{2}$; the east watershed is $1050 \mathrm{~km}^{2}$ in size; the remaining basins and sub-basins cover an area of $2827 \mathrm{~km}^{2}$. The main part of the Pinios watershed includes a mountainous terrain with altitudes higher than $2000 \mathrm{~m}$, as in the historically known Olympus (north) and Pindos (west), and agricultural plains, such as the Thessalic plain and urban areas with a mean elevation of $285 \mathrm{~m}$. 


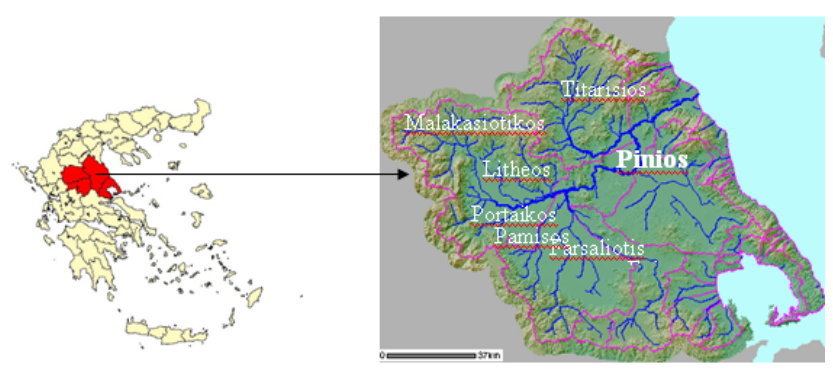

Figure 4. Geophysical map of Thessaly region.

The climate of the east part of Thessaly is a typical Mediterranean climate. In the west part of Thessaly, the climate is considered continental with cold winters, hot summers and a large seasonal temperature range. Indeed, summers are usually hot and dry with temperatures occasionally reaching $40^{\circ} \mathrm{C}$ in July and August. Mean annual precipitation over Thessaly is about $700 \mathrm{~mm}$, unevenly distributed in space and time, varying from about $400 \mathrm{~mm}$ at the central plain to more than $1850 \mathrm{~mm}$ at the western mountain peaks. The mountain areas receive significant amounts of snow during winter months. At the Thessalic plain, around Larissa and Karla watersheds, the mean annual precipitation has been reduced over the last 30 years by about $20 \%$ (Dalezios, 2011) and ranges between 250 to $500 \mathrm{~mm}$.

The Thessalic plain constitutes the main agricultural area of the country, with cotton still being the major crop. However, wheat, sugar beets, maize, barley, horticulture, fruits, olive trees and, recently, energy crops are also cultivated in the region. Since rainfall is, in general, rare from June to August, the resulted water deficit is replaced by irrigation in order to satisfy agricultural water needs. At the present time, in practical terms, the annual water availability is about 1023 million $\mathrm{m}^{3}$, consisting of surface $\left(623\right.$ million $\left.^{3}\right)$ and groundwater $\left(400\right.$ million $\left.\mathrm{m}^{3}\right)$, whereas the annual water needs amount to 1836 million $\mathrm{m}^{3}$. There is, thus, an annual water deficit of 813 million $\mathrm{m}^{3}$. Part of it (about 600 million $\mathrm{m}^{3}$ ) is expected to be covered from storage in a reservoir, known as Sykia Dam on the river Acheloos, which is under construction. Moreover, the amount of water used for irrigation purposes accounts for about $96 \%$ of the total water consumption. The irrigated areas have significantly increased over the last decades and are expected to further increase in Thessaly. Thus, future water needs are also expected to increase despite scheduled crop restructuring programmes. Thessaly is characterized by vulnerable agriculture, since extreme hydrometeorological events, such as floods, hail and droughts are quite common in the catchment, but also due to the existing water deficit for agriculture. Thessaly is considered as one of the most important agricultural regions in the country and drought episodes could have environmental and socioeconomic impacts. Droughts occur mainly due to reduced precipitation causing lack of soil moisture, increased evapotranspiration, increased vegetative stress, runoff reduction, decrease in streamflow levels in rivers, lakes and dams, lowering of the groundwater table, and thus resulting in water deficit for agriculture. The subject of this paper is agricultural drought and several drought features are explored through remote sensing, and analysed and presented in subsequent sections.

\subsubsection{Database}

For the VHI estimation, the following data are utilized. A time series of 10-day brightness temperature (BT) images extracted from channels 4 and 5 for 20 consecutive hydrological years (October 1981-September 2001) with a resolution of $8 \times 8 \mathrm{~km}^{2}$ provided by NOAA. Similarly, a time series of a 10-day NDVI extracted from channels 1 and 2 for 20 consecutive hydrological years (October 1981-September 2001) with a resolution of $8 \times 8^{2}$ provided by NOAA.

A database is developed for drought risk analysis and expected to be used in several components within the risk management framework. This database is based on recorded historical environmental data of the study area and consists of the following components. Digital information is collected on environmental factors, such as geology, geomorphology, soil, topography, agronomy, land use, land cover, geographic information system (GIS) and similar topics, which are used in susceptibility assessment. Information is also collected on triggering factors leading to drought, such as meteorological and hydrological parameters, e.g. rainfall and temperature, which are used in drought assessment. Also, a drought inventory is developed based on recorded historical drought episodes affecting agriculture. This drought inventory is used in susceptibility and hazard assessments. Finally, the exposed elements at risk are identified and recorded, such as crops, production, environmental degradation, farms, soil and similar aspects, which are used in exposure analysis and vulnerability assessment.

\subsection{Quantification of agricultural drought}

The estimation of VHI from remotely sensed data on a monthly basis follows certain steps. At first, preprocessing of satellite images is implemented, which includes geometric and atmospheric correction of all images, as well as certain filters for smoothing the data, which constitute an innovation of the procedure resulting in the improvement of VHI's performance (Domenikiotis et al., 2002). Then, the computation of the VHI is implemented and monthly VHI images of Thessaly are produced on a pixel basis. A brief description of the developed methodology follows.

\subsubsection{Preprocessing of satellite data}

All satellite data are obtained online from NASA archives. NDVI maps are 10-day maximum value composite (MVC) images produced from the original $\mathrm{CH} 1$ and $\mathrm{CH} 2$ images, 
visible and near infrared, respectively, of NOAA/AVHRR. Similarly, $\mathrm{CH} 4$ and $\mathrm{CH} 5$ images are converted to BT images using the equation provided by the information file of the data set. Using the 10-day images, NDVI and BT images are composed over a monthly period using the MVC and the mean pixel value, respectively. Missing data due to cloud cover or sensor's technical problems are filled up using monthly climatic values from time series of images with no blunders. Before using NDVI and BT images, fluctuations induced by noise must be removed. The combination of filtering and the MVC can significantly reduce the noise from residual clouds, fluctuating transparency of the atmosphere, target/sensor geometry, and satellite orbital drift (Goward et al., 1991). Other noise can be related to processing, data errors, or simple random noise (Kogan, 1995). In the present study, a "4253 compound twice" median filter (Van Dijk et al., 1987) is applied to NDVI images, whereas a "conditional" statistical mean spatial filter (window size ranging from $3 \times 3$ to $7 \times 7$, according to image needs) has been used for smoothing the BT series (Tsiros et al., 2009). The BT series presented continuous spatial fluctuations, and thus, a spatial filter (statistical mean) has been preferred for smoothing channel 4 and channel 5 BTs. The term "conditional" means that the filter is applied only to the pixels that present errors.

\subsubsection{Computation of VHI}

The computation of VHI is based on satellite data of temperature and the NDVI. The VHI is a combination of the VCI and the TCI, both derived from NOAA/AVHRR satellite data (Kogan, 2001). VCI and TCI, as well as VHI, as properly adjusted, have been successfully applied to Greece for the detection of agricultural drought and for monitoring agricultural crops (Dalezios et al., 2012b; Domenikiotis et al., 2002; Tsiros et al., 2004). A description of both VCI and TCI is presented followed by the computation of VHI.

The VCI is based on, and is an extension of, the NDVI. VCI scales the NDVI response of one image to the range of NDVI responses and, this way, quantifies the potential of regional responses (Kogan, 1995, 1997). VCI is related to the long-term minimum and maximum NDVI (Kogan, 2001) and is expressed by the following equation:

$\mathrm{VCI}=100 \times \frac{\mathrm{NDVI}-\mathrm{NDVI}_{\min }}{\mathrm{NDVI}_{\max }-\mathrm{NDVI}_{\min }}$,

where NDVI, NDVI $I_{\max }$ and $\mathrm{NDVI}_{\min }$ are the smoothed 10day NDVI, its multi-year maximum and its multi-year minimum, respectively, for each pixel in a given area. VCI values vary from 0 (for extremely unfavourable conditions) to 100 (for optimal conditions). The maximum amount of vegetation is developed in years with optimal weather conditions. Conversely, minimum vegetation amount develops in years with extremely unfavourable weather (mostly dry and hot). Thus, higher VCI values represent healthy and unstressed vegetation. VCI separates the short-term weather signal in the NDVI data from the long-term ecological signal (Kogan, 1997). VCI has excellent ability to detect drought and to measure the time of its onset and its severity, duration and impact on vegetation. The drought-monitoring VCI algorithm was developed and tested in several areas of the world with different environmental and economic resource (Kogan, 1995; Domenikiotis et al., 2002).

TCI is based on the same concept as VCI. Similarly, maximum amount of vegetation is developed in years with optimal weather conditions, whereas minimum vegetation amount develops in years with extremely unfavourable weather (mostly dry and hot). Therefore, the absolute maximum and minimum of BT, calculated for several years, contains the extreme weather events (drought and no drought conditions). The resulted maximum and minimum values can be used as criteria for quantifying the environmental potential of a region (Kogan, 1995, 1997). TCI is expressed by the following equation:

$\mathrm{TCI}=100 \times \frac{\mathrm{BT}_{\max }-\mathrm{BT}}{\mathrm{BT}_{\max }-\mathrm{BT}_{\min }}$,

where $\mathrm{BT}, \mathrm{BT}_{\max }$ and $\mathrm{BT}_{\min }$ are the smoothed 10-day radiant temperature, its multi-year maximum and its multi-year minimum, respectively, for each pixel in a given area. Similar to the VCI, TCI varies from 0 , for extremely unfavourable conditions, to 100 , for optimal conditions, and higher TCI values represent healthy and unstressed vegetation.

Kogan (2001) proposed the VHI, which represents overall vegetation health and is used for drought mapping and crop yield assessment. The five classes of VHI that represent agricultural drought, as well as no drought conditions (Bhuiyan et al. 2006), are illustrated in Table 2. Specifically, in Table 2, it is evident that drought severity is decreasing with increasing VHI values, i.e. class 1 refers to extreme drought with VHI values less than 10 , whereas, for VHI values greater than 40 , there is no drought. VHI is expressed by the equation:

$\mathrm{VHI}=0.5 \times(\mathrm{VCI})+0.5 \times(\mathrm{TCI})$.

In VHI computation, an equal weight has been assumed for both VCI and TCI, since moisture and temperature contribution during the vegetation cycle is currently not known. VCI and TCI vary from 0 , for extremely unfavourable conditions, to 100 , for optimal conditions.

VCI and TCI characterize the moisture and thermal conditions of vegetation, respectively (Kogan, 1995, 2001; Bhuiyan et al., 2006). Thermal conditions are especially important when moisture shortage is accompanied by high temperature, increasing the severity of agricultural drought and having a direct impact to vegetation health. In many parts of the world, TCI, along with VCI, has proven to be a useful tool for the detection of agricultural drought (Kogan, 2001; Bhuiyan et al., 2006; Tsiros et al., 2004). 
Table 2. VHI drought classification scheme (Kogan, 2001).

\begin{tabular}{llc}
\hline VHI values & $\begin{array}{l}\text { Vegetative } \\
\text { drought class }\end{array}$ & $\begin{array}{c}\text { drought classes } \\
\text { numbers }\end{array}$ \\
\hline$<10$ & Extreme drought & 1 \\
$<20$ & Severe drought & 2 \\
$<30$ & Moderate drought & 3 \\
$<40$ & Mild drought & 4 \\
$>40$ & No drought & \\
\hline
\end{tabular}

\subsection{Agricultural drought features}

As already mentioned, in order to assess and monitor drought, it is necessary to detect several drought features. Indeed, remote-sensing data and methods can delineate the spatial and temporal variability of several drought features in quantitative terms (Dalezios et al., 2012a). A description of some key features follows. Severity: severity or intensity of drought is defined as escalation of the phenomenon into classes from mild, moderate, severe and extreme. The severity is usually determined through drought indicators and indices, which include the above-mentioned classes. Duration: duration of a drought episode is defined as the time interval from the start and end time, usually in months. Since drought is a complex phenomenon, the assessment of start and end time is a complicated technical subject. Onset: the beginning of a drought is determined by the occurrence of a drought episode. The beginning of a drought is assessed through indicators or indices reaching certain threshold value. End time: end time of a drought episode signifies the termination of drought based, again, on threshold values of indicators or indices. Areal extent: areal extent of drought is considered the spatial coverage of the phenomenon as is quantified in classes by indicators or indices. Areal extent varies in time and remote sensing has contributed significantly in the delineation of this parameter by counting the number of pixels in each class.

\section{Analysis and discussion of results}

The results consist of quantification of drought through VHI estimation on a monthly basis for a period of 20 years (19812001) using satellite data. The analysis of results, besides quantification, also involves extraction of several drought features from VHI images, which lead to useful inferences. Moreover, the analysis of results includes evaluation and validation of the remotely sensed fitted monthly VHI series, in order to assess its accuracy and prognostic potential.

The results are presented in Table 3 (categories 1 and 2) and Table 4 (categories 3 and 4) and Figs. 5, 6, 7 and 8, respectively. At first, it should be mentioned that there is an on-going research effort on droughts in the study area of Thessaly. In a recent study on hydrological drought us- ing the reconnaissance drought index (RDI) based on satellite and conventional data (Dalezios et al., 2012a), there are eight detected drought periods lasting 12 months each within the same 20-year study period. However, in this paper, which deals with agricultural drought using VHI, and for the same period, drought occurs every year during the warm season, namely from May to October. This is shown in Tables 3 and 4, which present the cumulative areal extent of monthly VHI values throughout the warm season in number of pixels per severity class for the 20-year period, respectively. The above findings indicate that it would be advisable to jointly consider, at a later stage, the two different types of drought by merging RDI and VHI values, respectively, on a pixel basis for a holistic delineation of drought in the study area.

As already mentioned, the quantification of agricultural drought by using VHI has resulted into Tables 3 and 4. Indeed, the initial four VHI severity classes of the analysis have been merged into two in Table 3, namely extreme (class 1) and severe (class 2) drought into one class, and moderate (class 3) and mild (class 4) drought into another class (Table 4), respectively. The reason for merging classes is the small number of pixels in each class in order to develop a sizeable data set for fitting models. Tables 3 and 4 also show the monthly total and the average for the merged classes. The majority of pixels are accumulated between mild to moderate drought severity classes, indicating a significant decrease in the number of pixels from mild to extreme drought classes for all the months. Similarly, in Tables 3 and 4, it can be noted that the total seasonal extent in Thessaly for all of the years ranges in the same order of magnitude. Tables 3 and 4 also show the same increasing trend throughout each warm season. Furthermore, Table 3 indicates that there are years with very small areal extent at the beginning of the warm season, reaching small total areal extent at the end of the warm season. Similarly, Table 4 indicates that there are years with large areal extent at the beginning, reaching equally large total areal extent at the end of the warm season.

Figure 5 shows the histogram of the cumulative average monthly areal extent of the first two merged severity classes, namely extreme (class 1) and severe (class 2). Similarly, Fig. 6 shows the histogram of the other two merged severity classes, namely moderate (class 3 ) and mild (class 4) class. Figures 5 and 6 also indicate that most of the pixels are accumulated between mild to moderate severity classes with the peaks of severity and areal extent, respectively, appearing mainly towards the end of the summer. Moreover, Figure 7 shows the plotting of Figures 5 and 6 in one graph. Indeed, Figure 7 presents the cumulative monthly areal extent curves of the two merged classes, which correspond to the four VHI severity classes of agricultural drought. Furthermore, curve fitting is conducted for each of these curves, resulting in the following polynomials, namely Eq. (4) for high-severity areal extent drought and Eq. (5) for low-severity areal extent drought, respectively, both with a 
Table 3. Cumulative Areal Extent (number of pixels) of Monthly Drought VHI values (sum of severity classes 1 and 2).

\begin{tabular}{llllllll}
\hline Cummulative & May & Jun & Jul & Aug & Sep & Oct & Sum \\
\hline 1981 & 0 & 0 & 19 & 38 & 65 & 66 & 188 \\
1982 & 0 & 1 & 14 & 28 & 31 & 31 & 105 \\
1983 & 0 & 9 & 10 & 13 & 17 & 17 & 66 \\
198 & 0 & 1 & 6 & 10 & 10 & 10 & 37 \\
1985 & 0 & 12 & 30 & 58 & 71 & 71 & 242 \\
1986 & 0 & 3 & 13 & 25 & 33 & 33 & 107 \\
1987 & 0 & 0 & 7 & 8 & 17 & 17 & 49 \\
1988 & 0 & 10 & 24 & 36 & 40 & 40 & 150 \\
1989 & 1 & 19 & 36 & 43 & 53 & 53 & 205 \\
1990 & 3 & 39 & 57 & 69 & 69 & 69 & 306 \\
1991 & 0 & 0 & 1 & 2 & 2 & 2 & 7 \\
1992 & 0 & 2 & 3 & 5 & 5 & 5 & 20 \\
1993 & 0 & 1 & 2 & 10 & 10 & 10 & 33 \\
1994 & 0 & 0 & 0 & 0 & 0 & 0 & 0 \\
1995 & 0 & 0 & 17 & 20 & 20 & 20 & 77 \\
1996 & 1 & 13 & 18 & 19 & 19 & 19 & 89 \\
1997 & 0 & 0 & 2 & 2 & 3 & 3 & 10 \\
1998 & 0 & 2 & 3 & 11 & 12 & 12 & 40 \\
1999 & 0 & 6 & 6 & 7 & 7 & 7 & 33 \\
2000 & 1 & 2 & 12 & 17 & 18 & 18 & 68 \\
2001 & 0 & 7 & 15 & 15 & 15 & & 52 \\
& 6 & 127 & 295 & 436 & 517 & 503 & \\
\hline Average & 0.2857143 & 6.047619 & 14.047619 & 20.761905 & 24.619048 & 23.952381 \\
SD & 0.7171372 & 9.265399 & 13.843685 & 18.683963 & 22.44655 & 23.010924 & \\
Min & 0 & 0 & 0 & 0 & 0 & 0 & \\
\hline
\end{tabular}

high coefficient of determination.

$y=0.0905 x^{2}+4.3574 x\left(R^{2}=0.9168\right)$

$y=-3.7413 x^{3}+34.977 x^{2}-6.8352 x\left(R^{2}=0.9998\right)$

It is worth noting that the two curves of Fig. 7, namely the cumulative monthly areal extent curve of high severity classes (Eq. 4) and the corresponding curve of low severity classes (Eq. 5), respectively, delineate the range of values that agricultural drought may show every year during the warm season. Specifically, the curve of high severity classes (Eq. 4) shows, on average, 0.3 pixels in May with a maximum of 3 pixels, whereas in October, the curve shows an average of 24 pixels with a maximum of 71 pixels. Similarly, the curve of low severity classes shows an average of 25 pixels in May with a maximum of 84 pixels, whereas in October, the curve shows an average of 391 pixels with a maximum of 568 pixels. Indeed, at the beginning of the warm season in May, the low severity drought may start with average 25 pixels and may extend to 391 pixels in October, on average. On the other hand, the high-severity drought starts in May with an average of 0.3 pixels reaching 24 pixels in October, on average. These findings signify the possibility of using the fitted curves for monitoring and assessing drought in any region by implementing the described methodology in the previous section, where the actual VHI values may be different for different regions. In particular, for the study area of Thessaly, if at the beginning of the warm season in May there are close to 25 pixels or close to 0 pixels, this indicates that a low-severity or a high-severity drought, respectively, may be expected during the warm season.

In summary, the curves of Fig. 7 are fitted to the average values of data in Tables 3 and 4 and the corresponding Eqs. (4) and (5), respectively. Indeed, it seems that the average values of data support the curve fitting of the above Eqs. (4) and (5), respectively. Thus, the fitted curves of Fig. 7, along with the corresponding Eqs. (4) and (5), respectively, can be used for first-guess drought prognostic and monitoring assessment leading to early warning. Moreover, every year, new satellite images should be added to the database for the re-calculation of Eqs. (4) and (5), respectively. Also, with an increasing database, other options could also be considered, such as medians and modes, besides average values, as well as ground-truthing validation, in an effort to possibly improve drought prognostic potential and early warnings. Nevertheless, the developed curve fitting is a data-driven methodology, which is a standard remote-sensing approach. However, it is based on a large database of 20 years of satellite data with a high coefficient of determination. The analysis of results has indicated that this approach could be used 
Table 4. Cumulative areal extent (number of pixels) of monthly drought VHI values (sum of severity classes 3 and 4).

\begin{tabular}{|c|c|c|c|c|c|c|c|}
\hline Cummulative: & May & Jun & Jul & Aug & Sep & Oct & SUM \\
\hline 1981 & 0 & 0 & 123 & 252 & 343 & 418 & 1136 \\
\hline 1982 & 8 & 74 & 193 & 321 & 416 & 431 & 1443 \\
\hline 1983 & 36 & 142 & 228 & 331 & 433 & 464 & 1634 \\
\hline 198 & 6 & 72 & 173 & 266 & 308 & 332 & 1157 \\
\hline 1985 & 23 & 134 & 240 & 361 & 494 & 568 & 1820 \\
\hline 1986 & 45 & 139 & 249 & 350 & 471 & 513 & 1767 \\
\hline 1987 & 9 & 71 & 204 & 287 & 405 & 418 & 1394 \\
\hline 1988 & 19 & 108 & 243 & 359 & 467 & 541 & 1737 \\
\hline 1989 & 18 & 107 & 211 & 315 & 408 & 474 & 1533 \\
\hline 1990 & 84 & 169 & 298 & 422 & 511 & 561 & 2045 \\
\hline 1991 & 0 & 38 & 129 & 203 & 266 & 306 & 942 \\
\hline 1992 & 16 & 103 & 174 & 265 & 323 & 374 & 1255 \\
\hline 1993 & 12 & 94 & 173 & 260 & 310 & 352 & 1201 \\
\hline 1994 & 9 & 60 & 101 & 154 & 213 & 236 & 773 \\
\hline 1995 & 4 & 44 & 146 & 215 & 278 & 318 & 1005 \\
\hline 1996 & 49 & 148 & 237 & 309 & 338 & 347 & 1428 \\
\hline 1997 & 27 & 124 & 228 & 291 & 358 & 379 & 1407 \\
\hline 1998 & 25 & 106 & 196 & 284 & 336 & 365 & 1312 \\
\hline 1999 & 40 & 145 & 227 & 305 & 357 & 376 & 1450 \\
\hline 2000 & 43 & 129 & 243 & 337 & 421 & 431 & 1604 \\
\hline \multirow[t]{2}{*}{2001} & 45 & 141 & 229 & 299 & 345 & & 1059 \\
\hline & 518 & 2148 & 4245 & 6186 & 7801 & 8204 & \\
\hline Average & 24.666667 & 102.28571 & 202.14286 & 294.57143 & 371.47619 & 390.66667 & \\
\hline SD & 21 & 43 & 49 & 60 & 79 & 89 & \\
\hline Min & 0 & & & & & & \\
\hline Max & 84 & 169 & 298 & 422 & 511 & 568 & \\
\hline
\end{tabular}

VHI distribution

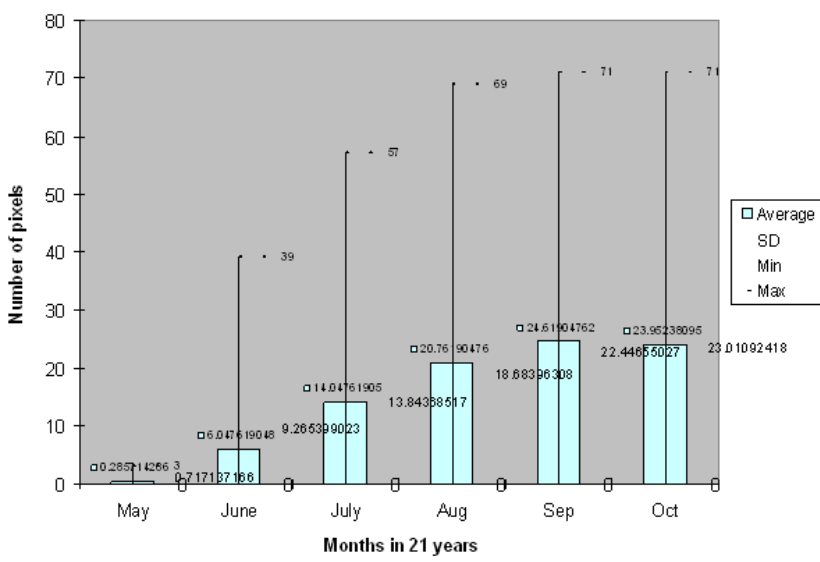

Figure 5. Histogram of cumulative areal extent (number of pixels) of average monthly drought VHI values (sum of severity classes 1 and 2).

operationally on a monthly basis every year starting in May as a drought early warning indicator with sufficient confidence.
VHI distribution

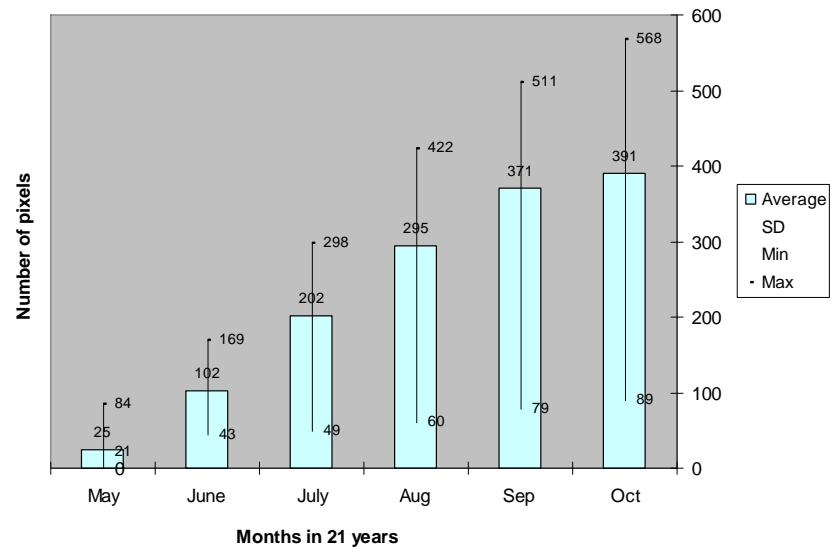

Figure 6. Histogram of cumulative areal extent (number of pixels) of average monthly drought VHI values (sum of severity classes 3 and 4).

It is felt that it should also be mentioned that irrigation is a common agricultural practice during the warm season in the study area, which may affect drought analysis. Indeed, the purpose of the approach presented in this paper is to 


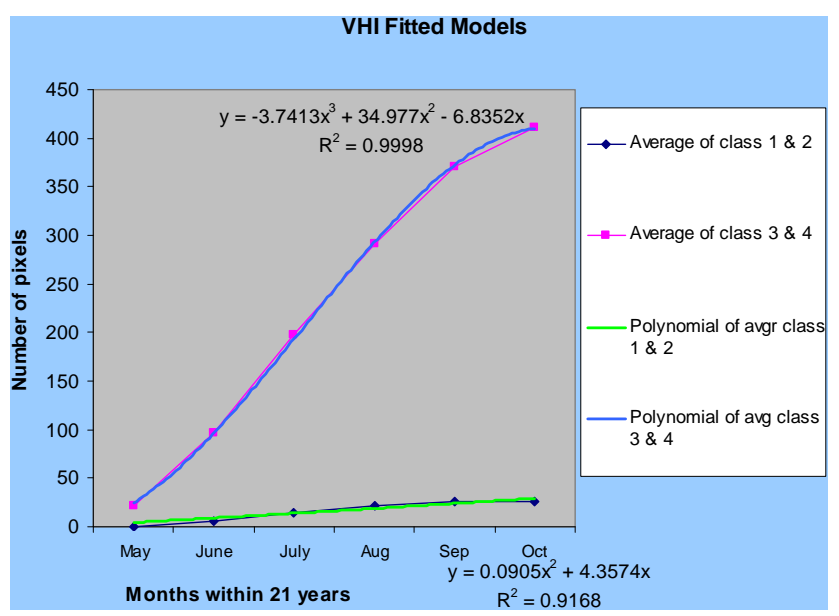

Figure 7. Fitted models of cumulative areal extent (number of pixels) of average monthly drought VHI values for the two sums of severity classes.

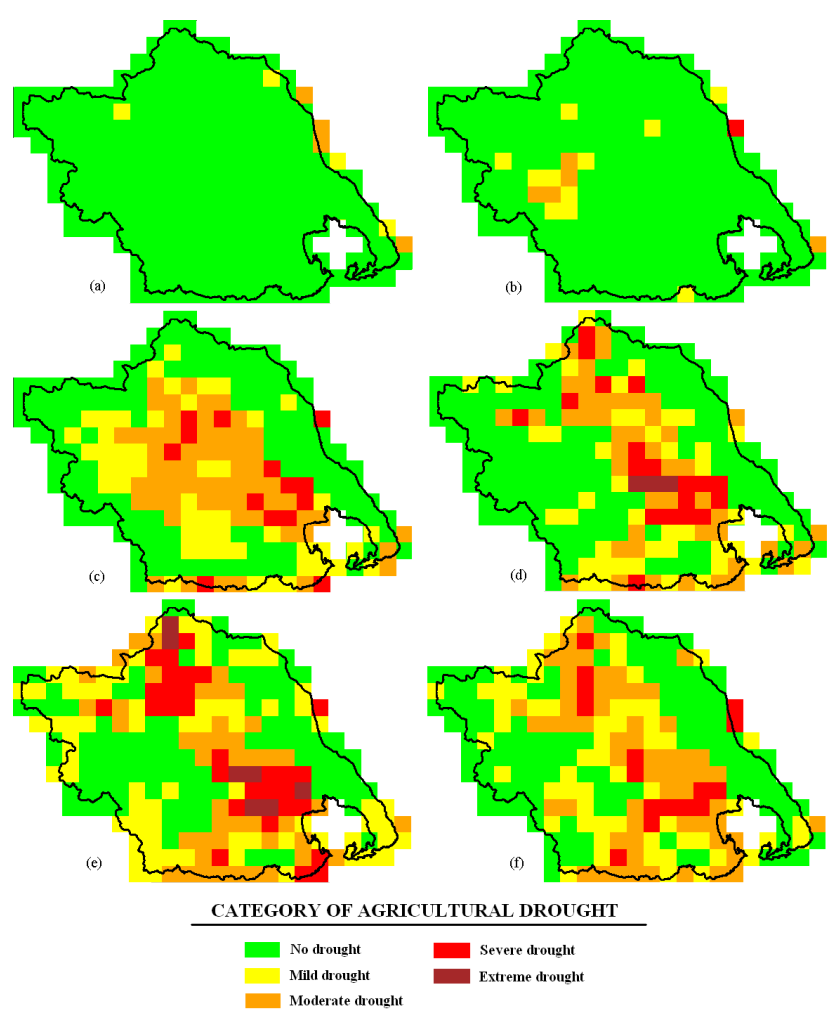

Figure 8. VHI map of Thessaly for 6 months (April-September 1985) (from Kanellou et al., 2009) (a) April 1985, (b) May 1985, (c) June 1985, (d) July 1985, (e) August 1985, (f) September 1985.

develop a remote-sensing methodology under conditions of existing agricultural practice, including irrigation, and the results have shown consistency, which has also been achieved in similar recent studies in the study area (Dalezios et al., 2012a; Kanellou et al., 2009a, 2012).
Finally, for illustrative purposes, Fig. 8 presents VHI drought severity mapping of Thessaly for six months, namely from April to September 1985 (Kanellou et al., 2009a). In Fig. 8, it is evident that drought starts occurring in May with increasing severity and areal extent throughout the warm season with the maximum occuring towards the end of the summer, as expected. Figure 8 also shows the spatial variability of drought severity and extent within Thessaly, as well as delineating the areas of drought persistence.

\section{Conclusions}

In this paper, VHI is developed based on remote-sensing and GIS data and techniques. VHI monitors agricultural drought and is estimated on a monthly basis. The data set covers a period of 20 hydrological years, from October 1981 to September 2001. The study area is the region of Thessaly, in central Greece, which is a drought-prone agricultural region characterized by vulnerable agriculture. The results indicate that drought occurs every year during the warm season, starting in May, with increasing severity and areal extent throughout the warm season with the maximum occurring in September. The results also show that, mostly, in central, northwest and southeast parts of Thessaly (Fig. 8), drought occurrence persists. Fitted models of drought cumulative areal extent for different severity classes based on VHI values are used for quantitative drought assessment with a very high coefficient of determination.

It is clear that remote sensing has indicated some new capabilities in assessing and monitoring the spatiotemporal variability of drought. Several drought features are analysed from the monthly VHI images, namely severity, duration, areal extent, onset and end time. The majority of pixels is accumulated between mild to moderate drought severity classes indicating a significant decrease in the number of pixels from mild to extreme drought classes for all the months. Similarly, in Table 3, it is noted that the total areal extent in Thessaly for all of the years ranges in the same order of magnitude. Moreover, there is no significant increase in the areal extent from class 1 to class 4 . Tables 3 and 4 also show the same increasing trend throughout each warm season. There is also an increase in the areal extent of drought during each drought period with the maximum usually occurring towards the end of the summer. Finally, the fitted curves of Fig. 7, along with the corresponding Eqs. (4) and (5), respectively, can be used for first-guess drought prognostic and monitoring assessment leading to early warning systems.

Acknowledgements. This research was funded by Pleiades, Smart and Hydrosense EC projects. The satellite data was provided by NOAA. The software ERDAS Imagine 8.7 is used in the analysis.

Edited by: P. Nastos

Reviewed by: two anonymous referees 


\section{References}

Bhuiyan, C., Singh, R. P., and Kogan, F. N.: Monitoring drought dynamics in the Aravalli region (India) using different indices based on ground and remote sensing data. International Journal of Applied Earth Observation and Geoinformation, 8, 289-302, 2006.

Dalezios, N. R., Loukas, A., Vasiliades, L., and Liakopoulos, H.: Severity-Duration-Frequency Analysis of Droughts and Wet Periods in Greece, Hydrol. Sci. J., 45, 751-770, 2000.

Dalezios, N. R., Bampzelis, D., and Domenikiotis, C.: An integrated methodological procedure for alternative drought mitigation in Greece, European Water, 27/28, 53-73, 2009.

Dalezios, N. R.: Climatic change and Agriculture: ImpactsMitigation-Adaptation, Scientific Journal of GEOTEE., 27, 1328, 2011.

Dalezios, N. R., Blanta, A., and Spyropoulos, N. V.: Assessment of remotely sensed drought features in vulnerable agriculture, Nat. Hazards Earth Syst. Sci., 12, 3139-3150, doi:10.5194/nhess-123139-2012, 2012a.

Dalezios, N. R., Blanta, A., and Spyropoulos, N. V.: Remotely Sensed Spatiotemporal Features of Agrometeorological Drought, 11h International Conference on Meteorology, Climatology and Atmospheric Physics, sponsored by Springer and the Association, Athens, 29 May-1 June, 409-414, 2012b.

Domenikiotis, C., Spiliotopoulos, M., Tsiros, E., and Dalezios, N. R.: Application of NOAA/AVHRR VCI for drought monitoring in Thessaly, 6th International Conference of Protection and Restoration of the Environment, 1-5 July, Volos, Greece, 16631670, 2002.

Domenikiotis, C., Spiliotopoulos, M., Tsiros, E., and Dalezios, N. R.: Early Cotton Yield Assessment by The Use Of The NOAA/AVHRR Derived Drought Vegetation Condition Index In Greece, Int. J. Remote Sens., 25, 2807-2819, 2004.

EU: Green Paper Adapting to Climate Change in Europe - Options for EU Action.COM (2007), 354, Brussels, 27 pp., 2007.

Farrell, D., Trotman, A., and Cox, C.: Drought Early Warning and Risk Reduction: a Case Study of the Carribbean Drought of 2009-2010. Global Assessment Report: GAR 2011 on Disaster Risk Reduction, UNISDR, 22 pp., 2010.

Foot, J. S.: Hazard warning in meteorology: theimportance of remote sensing, in: Proceedings of IDNDR Conference on Natural Hazards and Remote Sensing, London, UK, 8-9 March, 13-16, 1993.

Goward, S. N., Markham, B., Dye, D. G., Dulaney, W., and Yang, J.: Normalized Difference Vegetation Index measurements from the advanced very high resolution radiometer, Remote Sens. Einviron., 35, 257-277, 1991.

Heim Jr., R. R.: A Review of Twentieth-Century Drought Indices Used in the United States, B. Am. Meteorol. Soc., 83, 1149$1165,2002$.

IPCC: Managing the Risks of Extreme Events and Disasters to Advance Climate Change Adaptation, Special Report of IPCC, 582 pp., 2012.

Kanellou, E. C., Domenikiotis, C., Tsiros, E., and Dalezios, N. R.: Satellite-based Drought Estimation in Thessaly. European Water, 23/24, 111-122, 2009a.

Kanellou, E. C., Domenikiotis, C., and Dalezios, N. R.: Description of Conventional and Satellite Drought Indices, 23-59, edited by: Tsakiris, G., PRODIM Final Report, EC, 448 pp., 2009 b.
Kanellou, E. C., Spyropoulos, N. V., and Dalezios, N. R.: Geoinformatic Intelligence Methodologies for Drought Spatiotemporal Variability in Greece, Water Resour. Manag., 26, 1089-1106, 2012.

Keyantash, J. and Dracup, J. A.: The Quantification of Drought: An Evaluation of Drought Indices, B. Am. Meteorol. Soc., 83, 1167-1180, 2002.

Kogan, F. N.: Application of vegetation index and brightness temperature for drought detection, Adv. Space Res., 15, 91-100, 1995.

Kogan, F. N.: Global drought watch from space, B. Am. Meteorol. Soc., 78, 621-636, 1997.

Kogan, F. N.: Operational space technology for global vegetation assessment, B. Am. Meteorol. Soc., 82, 1949-1964, 2001.

Mishra, A. K. and Singh, V. P.: A Review of Drought Concepts, J. Hydrology, 39, 202-216, 2010.

McVicar, T. R. and Jupp, D. L. B.: The Current and Potential Operational Uses of Remote Sensing to Aid Decisions on Drought Exceptional Circumstances in Australia: a Review, Agricultural Systems, 57, 399-468, 1998.

Peng, L. Y., Wei, Y., Meng, W., and Dong, Y. X.: Climate Change and Drought: a risk assessment of crop-yield impacts, Clim. Res., 39, 31-46, 2009.

Piechota, T. C. and Dracup, J. A.: Drought and Regional Hydrology Variation in the United States: associations with the El Nino Southern Oscillation, Water Resour. Res., 32, 1359-1373, 1996.

Salinger, J., Sivakumar, M. V. K., and Motha, R. P. (Eds.): Increasing Climate Variability and Change: Reducing the Vulnerability of Agriculture and Forestry, Springer, ISBN 1-4020-3354-0, 362 pp., 2005.

Shahid, S. and Behrawan, H.: Drought Risk Assessment in the Western part of Bangladesh, Nat. Hazards, 46, 391-413, 2008.

Sivakumar, M. V. K., Wilhite, D. A., Svoboda, M. D., Hayes, M., and Motha, R.: Drought and Meteorological Droughts, Global Assessment Report: GAR 2011 on Disaster Risk Reduction, UNISDR, 26 pp., 2010.

Sivakumar, M. V. K., Motha, R. P., and Das, H. P. (Eds.): Natural Disaster and Extreme Events in Agriculture, Springer, ISBN-10 3-540-22490-4, 367 pp., 2005.

Smith, K.: Environmental Hazards: Assessing Risk and Reducing Disaster. Routledge, 3rd Edition, ISBN0-415-22463-2, 398 pp., 2001.

Steinemann, A., Hayes, M. A., and Cavalcanti, L.: Drought Indicators and Triggers, in: Drought and Water Crises, Science Technology and Management Issues, edited by: Wilhite, D. A., Marcer Dekker Publ., 71-90, 2005.

Steven, M. D. and Jaggard, K. W.: Advances in Crop Monitoring by Remote Sensing, in: Advances in Environmental Remote Sensing, edited by: Danson F. M. and Plummer S. E., Wiley, 143-156, 1995.

Tarquis A. M., Gobin, A., Dalezios, N. R., and Ulbrich, U. (Eds): Weather Related Hazards and Risks in Agriculture, Special Issue, Nat. Hazards Earth Syst. Sci., in press, 2013.

Thenkabail, P. S., Gamage, M. S. D. N., and Smakhtin, V. U.: The Use of Remote Sensing Data for Drought Assessment and Monitoring in Southwest Asia. Research Report, International Water Management Institute, No. 85, 125, 2004.

Tsiros, E., Domenikiotis, C., Spiliotopoulos, M., and Dalezios, N. R.: The use of NOAA/AVHRR-based vegetation condition in- 
dex (VCI) and temperature condition index (TCI) for drought monitoring in Thessaly, Greece, EWRA Symposium on water resources management: risks and challenges for the 21 st century, Izmir, Turkey, 2-4 September 2004, 769-782, 2004.

Tsiros E., Domenikiotis, C., and Dalezios, N. R.: Sustainable production zoning for agroclimatic classification using GIS and remote sensing, IDŐJÁRÁS, 113, 55-68, 2009.

Tucker, C. J. and Choudhury, B. J.: Satellite remote sensing of drought conditionsm, Remote Sens. Environ., 23, 243-251, 1987.

UN/ISDR: Hyogo Framework for Action 2005-2015, World Conf. on Disaster Reduction, Final Report, 18-20 Jan. 2005, Kobe, Hyogo, Japan, 22 pp. (www.unisdr.org), Abstract number A/Conf.206/6, 2005.
Van Dijk, A., Callis, S. L., and Sakamoto, C. M.: Smoothing vegetation index profiles: An alternative method for reducing radiometric disturbance in NOAA/AVHRR data, Journal of Photogrammetric Engineering \& Remote Sensing, 63, 1059-1067, 1987.

Wang J., Rich, P. M., and Price K. P.: Temporal responses of NDVI to precipitation and temperature in the central Great Plains, USA, Int. J. Remote Sens., 24, 2345-2364, 2003.

Wilhite, D. A., Hayes, M. J., Kinutson, C., and Smith, K. H.: Planning for drought: moving from crisis to risk management, J. Amer. Water Res. Assoc., 36, 697-710, 2000.

Wu, H. and Wilhite, D. A.: An Operational Agricultural Drought Risk Assessment Model for Nebraska, USA, Nat. Hazards, 33, 1-21, 2004. 